\title{
Interferons in cancer immunoediting: sculpting metastasis and immunotherapy response
}

\author{
Michelle von Locquenghien, Catalina Rozalén, and Toni Celià-Terrassa
}

Cancer Research Program, IMIM (Hospital del Mar Medical Research Institute), Barcelona, Spain.

Interferons (IFNs) are pleiotropic cytokines critical for regulation of epithelial cell functions and for immune system regulation. In cancer, IFNs contribute to tumor-intrinsic and -extrinsic mechanisms that determine the quality of antitumor immunity and response to immunotherapy. In this Review, we focus on the different types of tumor IFN sensitivity that determine dynamic tumor-immune interactions and their coevolution during cancer progression and metastasis. We extend the discussion to new evidence supporting immunotherapy-mediated immunoediting and the dual opposing roles of IFNs that lead to immune checkpoint blockade response or resistance. Understanding the intricate dynamic responses to IFN will lead to novel immunotherapeutic strategies to circumvent protumorigenic effects of IFN while exploiting IFNmediated antitumor immunity.

\section{Introduction}

Interferons (IFNs) were discovered by Alick Isaacs and Jean Lindenmann in 1957 as regulator cytokines against virus infections, interfering in viral replication (1). These secreted cytokines are potent inducers of growth arrest, differentiation, inflammation, and immunity (2-5). Furthermore, IFNs have a central function in orchestrating adaptive and innate antitumor immune responses (6-8). Distinct IFN types drive specific gene expression signatures that can be largely overlapping and crosstalk with other pathways in a context-dependent manner (9), thus generating dynamic cascades of signals evolving into basal, augmented, and desensitized IFN responses $(10,11)$. As a consequence, IFNs have pleiotropic and opposing roles that act at multiple levels of the tumorimmune interface, shaping tumor and metastasis dynamics as well as therapeutic responses.

The concept of immunosurveillance was postulated by Lewis Thomas and Frank Macfarlane Burnet during the mid-20th century, proposing the immune system's role in detection and elimination of malignant transformed cells $(12,13)$. Schreiber and colleagues described initial functional experimental evidence of immunosurveillance showing IFN- $\gamma$ signaling's critical role in governing antitumor immune responses (14). Later, their work with genetically modified mouse models lacking IFN- $\gamma$ sensitivity (IFNGR- or STAT1-deficient mice) showed aggressive carcinogenesis in multiple organs due to low immunogenicity and failure of immune detection (15), which suggested IFN as a central node of cancer immunosurveillance. In addition, a seminal study using immunodeficient $R A G 2^{-/-}$mice, which are incapable of generating mature $\mathrm{B}$ and $\mathrm{T}$ cells, showed that immune defense is necessary to halt tumorigenesis and that this effect depends on IFN-mediated immunogenicity in tumor cells (16). IFN-nonresponsive tumor

Conflict of interest: The authors have declared that no conflict of interest exists. Copyright: (c) 2021, American Society for Clinical Investigation.

Reference information: J Clin Invest. 2021;131(1):e143296.

https://doi.org/10.1172/JCl143296. cells were poorly immunogenic and were selected as a result of immune pressure, enabling escape from immunosurveillance and tumor outgrowth. This coevolutionary interplay between tumor cells and the immune system was termed "cancer immunoediting" $(17,18)$, and IFN signaling is a cornerstone of the process.

IFNs have traditionally been used for cancer treatment because of their pleiotropic antitumor effects. Interestingly, at the end of the 19th century, William B. Coley - the "father of immunotherapy" - pioneered cancer treatments by harnessing the immune system and showed that inactivated endotoxins from Streptococcus pyogenes led to tumor regressions through a LPS-induced immune response governed by IFNs $(19,20)$. The first FDA-approved human immunotherapeutic agent was IFN- $\alpha 2$ in 1986 (21); however, its variable responses and side effects reduced the interest in IFNs. With the emergence of immune checkpoint blockade (ICB) therapy, new IFN-based strategies should be considered, as IFNs appear to be crucial in immunotherapy responses (22-24). It is now well known that IFNs play critical roles in immunotherapy $(25,26)$, yet mechanistic dynamics of IFN during therapy responses and resistance require further investigation.

In this Review, we discuss how IFNs confer host-protective cancer-eliminating functions, how mechanisms of IFN insensitivity shape tumor immunogenicity during cancer progression and metastasis, and how IFNs participate in modification of tumor attributes that contribute to cancer escape and progression. We shed light on the implications of IFNs in metastasis and immunotherapy resistance, especially for ICB, and their clinical relevance toward opening new avenues in cancer immunotherapy.

\section{IFN signaling in cancer}

The family of IFNs in humans is classified on the basis of structural features, receptor usage, genomic location, and function in three distinct groups: type I (IFN- $\alpha$, IFN- $\beta$, IFN- - , IFN- $\kappa$, and IFN- $\omega$ ), type II (IFN- $\gamma$ ), and type III (IFN- $\lambda$ ) (6). Their canonical signaling consists of JAK/STAT pathway activation. Type I and III IFNs signal through distinct heterodimeric IFN receptors and TYK2/ 
JAK1, while type II uses homomeric IFN receptors and JAK1/JAK2 kinases. All IFNs regulate various associations with STATs and induce interferon-stimulated genes (ISGs) and interferon-regulatory factors (IRFs) to trigger IFN response, as recently reviewed in more detail $(5,21,27)$. Despite differences in signaling, IFN gene expression signatures largely overlap and, hence, are challenging to distinguish between types.

Most cells have the ability to produce type I IFNs as mechanisms of antiviral defense, while high type III IFN expression is largely found in epithelial cells. In the tumor microenvironment (TME), IFN- $\alpha$ and IFN- $\beta$ are produced by innate and adaptive immune responses but also by malignant tumor cells $(5,21)$. Their production is prompted by various damage-associated molecular patterns (DAMPs) via pattern recognition receptors such as TLRs (28) and cytosolic RNA-specific RIG-I-like receptors (RLRs) (29) that sense pathogen-exogenous and endogenous damagedderived nucleic acids, and via cytoplasmic DNA sensors through the cyclic GMP-AMP synthase (cGAS) and stimulator of IFN genes protein (STING) pathway (30). Interestingly, plasmacytoid dendritic cells (pDCs), which synthesize large amounts of IFN- $\alpha$, are restricted to the expression of TLR9 (31). Type II IFN is mainly produced by NK cells, NKT cells, and subsets of $\mathrm{CD} 4^{+}$and $\mathrm{CD} 8^{+} \mathrm{T}$ cells in response to antigens (27).

In cancer, IFN signaling mediates intrinsic and extrinsic effects on tumor cells and the TME, including tumor-infiltrating lymphocytes or tumor-associated stroma (32). Besides playing a role in tumor prevention via IFNAR1/IFN- $\alpha / \beta$ signaling (33), IFNs exert direct intrinsic antitumor effects including inhibition of cell proliferation by induction of cell cycle arrest and apoptosis (34$36)$, ferroptosis $(37)$, cell differentiation $(38,39)$, and senescence $(39,40)$, thus acting as a tumor suppressor.

Remarkably, IFN response is a master regulator of tumor immunogenicity via cell-intrinsic control of the antigen processing and presentation machinery (APM) pathways by MHC classes I and II, which are required for adaptive immune detection in antigen-presenting cells and tumor cells. It has long been reported that IFNs control upregulation of MHC (41-43), B2M (which is essential for MHC class I antigen presentation) (44), and transporter proteins TAP1 and TAP2 (45). Moreover, IFNs coordinate the immunoproteasome through its subunits PSMB8, PSMB9, or PSMB10. As a result of genomic instability, the immunoproteasome cleaves polypeptides into neopeptides recognized as foreign molecules by the immune system (46). However, IFN- $\gamma$ exposure leads to expression of inhibitory receptors such as PD-L1/2 (47), CTLA-4 (48), or the immunosuppressive metabolite indoleamine 2,3-dioxygenase (IDO) (49), which are mechanisms of adaptive immune resistance (50). Although this normally occurs to prevent chronic inflammatory processes, in cancer, it serves as an immune evasion mechanism (10). Moreover, depending on the cellular context, IFNs have opposing functions in cancer, such as proliferative effects (51) via upregulation of NF- $\mathrm{B}$ (52). Under chronic IFN exposure, STAT3 activation fuels tumor growth while inhibiting antitumor actions of IFNs through expression of JAK inhibitors, such as the suppressors of cytokine signaling 1 and 3 (SOCS1 and SOCS3) (53).

Among their extrinsic effects, the most relevant antitumor effects of IFNs involve their vast influence on innate and adaptive immunity. IFNs upregulate the expression of MHC class I and II, costimulatory molecules (e.g., CD80 and CD86), and other immunomodulatory ISGs in DCs $(4,54)$, which promote activation and cytotoxicity of $\mathrm{CD}^{+} \mathrm{T}$ cells $(55,56)$ and differentiation of $\mathrm{CD} 4^{+}$ $\mathrm{T}$ cells into Th1 cells (57). IFNs polarize tumor-associated macrophages toward an antitumorigenic, inflammatory M1 phenotype (58) and decrease accumulation of myeloid-derived suppressor cells (MDSCs) (59) and Tregs (60). IFN-mediated cytokine synthesis of IL-15 can activate NK cell-mediated tumor cytolysis (61-63). In contrast, persistent IFN exposure has protumorigenic effects by expanding Tregs (64) and attracting immunosuppressive MDSCs (65), which produce nitric oxide (NO), leading to dampened STAT1 activation and host immune response (66).

\section{Tumor primary and acquired insensitivity to IFNs}

Tumors exhibit high genomic and phenotypic heterogeneity, which underlies the observed differences of tumor responses to IFN signaling inputs. For instance, genomic alterations and deletions in IFN receptors or mediators are commonly found in several cancer types, which partially reduce their ability to respond (67-70). The loss of response to IFNs gives cancer cells growth advantages and leads to tumor development, hence underscoring the tumor-suppressive intrinsic and extrinsic effects of IFNs. In contrast, specific phenotypic traits such as stemness are associated with low capacity to respond to IFN, as shown in normal and cancerous mammary stem cells (39). Therefore, distinct tumor cells have divergent responsive capacity to IFN cues, eventually evolving tumors with low sensitivity as the result of developing selective survival advantages, which aligns with the law of natural selection.

Herein, we propose two types of IFN insensitivity in tumors (Figure 1): (a) primary IFN insensitivity due to mutations (67-69) or epigenetic marks (71-73) present at carcinogenesis, independent of the TME interactions; and (b) acquired IFN insensitivity can be caused by avoidance of IFNs' antiproliferative activity but mainly by circumvention of immune pressure during immunoediting, leading to clonal selection of insensitive genotypes/phenotypes or dynamic phenotypic conversions during cancer progression. This can be further intensified in boosted immunity through immunotherapies. We envision cancer immunoediting as a determinant process for acquired IFN insensitivity (Figure 1).

In primary IFN insensitivity, established tumors do not respond to IFN signals. These tumors arise with genomic or epigenomic alterations of IFN mediators endowing malignant properties. In various cancers, the loss of STAT1 or inactivating mutations disrupting IFN signaling have been observed (74), while STAT1 expression correlates with better prognosis $(75,76)$. Defects in IFNAR1 and IFNAR2 $(77,78)$ and mutations in JAK1 and JAK2 in tumors also result in IFN insensitivity. SOCS factors inhibit JAK/ STAT pathways and regulate IFN sensitivity by reducing apoptosis in pancreatic cancer (80). In experimental studies, Meth-A fibrosarcoma tumor cells overexpressing a truncated dominantnegative form of IFNGR1 (i.e., IFN- $\gamma$-insensitive cells) grew more aggressively than control tumor cells (14). In addition, genetically engineered mouse models lacking Ifngr or Stat1 are unable to respond to IFN signaling, and the use of these models revealed even greater tumor incidence (15). 
Primary IFN insensitivity

Genomic and epigenetic alterations of IFN genes

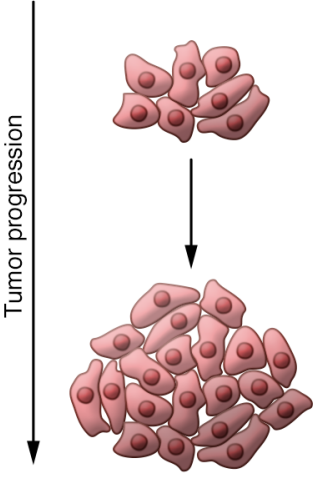

IFN-insensitive tumor cell

\section{Acquired IFN insensitivity}

Genotypic or phenotypic clonal expansion
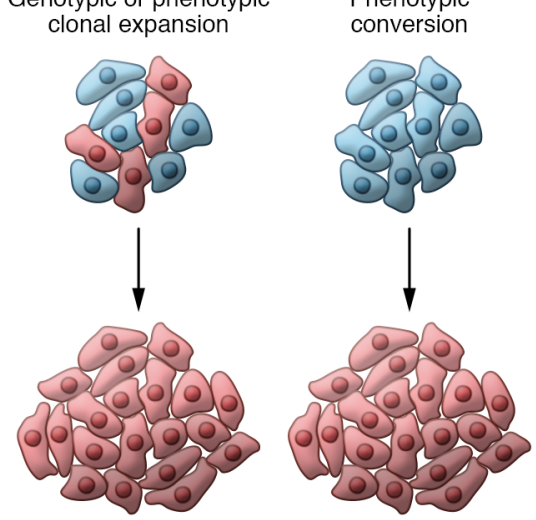

IFN-sensitive tumor cell

Figure 1. Types of IFN insensitivity: primary and acquired. Primary IFN insensitivity arises from mutations or epigenetic marks, leading to IFN-insensitive tumor cells. Acquired IFN insensitivity can be generated from tumors that initially respond to IFN but, as a result of clonal selection or phenotypic conversions, turn insensitive. Both types are driven and sustained by two forces of tumor evolution: tumor progression and immunoediting.

Acquired IFN insensitivity is generated in tumors that initially respond to IFN signals but shift toward an IFN-nonresponsive state during cancer progression. In fact, the clonal selection of poorly immunogenic clones was recently demonstrated (81). A recent experimental study showed that in heterogeneous tumor settings, clones with Ifngr 2 or Jak1 deletions are positively selected as a result of IFN insensitivity, but not when those deficiencies are homogeneous in the tumor population, similar to primary IFN insensitivity populations (82). This study indicates that acquired IFN insensitivity drives more malignant features than primary IFN insensitivity. Under augmented immune pressure, tumor cells acquire mutations and defects in IFN signaling $(23,78,79)$, to exploit its protumorigenic effects while being insensitive to its antitumor functions. Along with cancer progression and metastasis, tumors silence IRF1 and STAT1, causing reduced MHC class II expression as an immune evasion mechanism (83). Emerging studies also reveal that cell fate regulators, such as LCOR, can modulate IFN responses, since LCOR loss induces cancer stem cell (CSC) properties and IFN insensitivity; conversely, LCOR upregulation primes cells that are highly sensitive to IFN signals $(39,84)$. Another study in triple-negative breast cancer (TNBC) showed that IFN signal transduction in CSC populations is blocked by reduced ISG3 phosphorylation (85). Also, CD133 ${ }^{+}$CSCs were shown to be insensitive to IFN- $\gamma$-mediated autophagy (86). Ultimately, stem cell phenotypes are linked to reduced IFN sensitivity, conferring advantageous properties for sustained tumor progression.

\section{Cancer metastasis immunoediting and IFN sensitivity}

The concept of cancer immunoediting delineates three phases - elimination, equilibrium, and escape - of tumor-immune coevolution during cancer progression, in which immune attack executes anticancer actions, but the failure to complete tumor eradication results in selection of immune-evasive tumors, contributing to their aggressiveness (87). Recent studies shed light on the extension of immunoediting beyond the primary sites. Once disseminated, tumor cells encounter new immune interactors in distant tissues (88-90), and the immune system continuously exerts immune pressure that recapitulates the phases of immunoediting and enhances editing of metastatic tumors (Figures 2 and 3). Although how the immune microenvironment affects tumor evolution in diverse metastatic organs remains to be determined $(81,91)$, two recent studies demonstrate the influence of organ-immune contexture in sculpting and generating heterogeneous metastatic lesions in different sites corresponding with different prognoses in ovarian cancer metastasis (92, 93). Even though both studies represent evidence of metastasis immunoediting, neither reported the impact of immunity on clonal tumor evolution. Remarkably, another study showed how the immunity of different metastatic sites influences the clonal evolution of metastasis and thus results in outgrowth of immune-privileged clones (81).

The foundation of the concept of immunoediting is the suppressive effect of the immune system on IFN- $\gamma$-sensitive immunogenic tumors, which are negatively selected by immune pressure; the resultant IFN-insensitive tumor cells escape immune detection and grow without IFN-suppressive constraints (16). IFN sensitivity plays key roles in the three phases of cancer immunoediting: cancer detection and elimination; dynamic equilibrium of immune-mediated killing and maintenance of proliferating, indolent cancer cells; and immune escape and outbreak of more aggressive tumor phenotypes (87). To date, several studies have demonstrated how IFNs intervene as a central axis in all three phases (see other specialized reviews, refs. 7, 17; and Figure 2). We focus on IFN's dynamic sensitivity in tumor cells, which determines the pace of cancer immunoediting (Figure 2) and the sculpture of metastasis evolution.

Elimination phase. Initial studies using neutralizing monoclonal antibodies (mAbs) to block IFN- $\gamma$ in mice or mouse models with tumor IFN response deficiencies showed that IFN sensitivity is fundamental in mediating the expression of MHCs and the other APM factors, and thus conveying the immunogenicity for tumor elimination (14-16). Accordingly, ectopic expression of APM factors, such as TAP1 in Ifngr/- tumors (16) as well as in other models (94), restores the APM, preventing escape and facilitating tumor elimination by the immune system. In addition, IFNs contribute to tumor suppression by intrinsic actions such as proliferation inhibition, apoptosis induction $(34,95)$, and necrosis $(96)$, resulting in impaired tumor progression and eradication (Figure 2). IFNs increase the cytotoxic activity of both innate and adaptive immunity (7). Overall, during the elimination phase, tumor growth is inhibited, and cancer cells are eliminated by innate and adaptive 


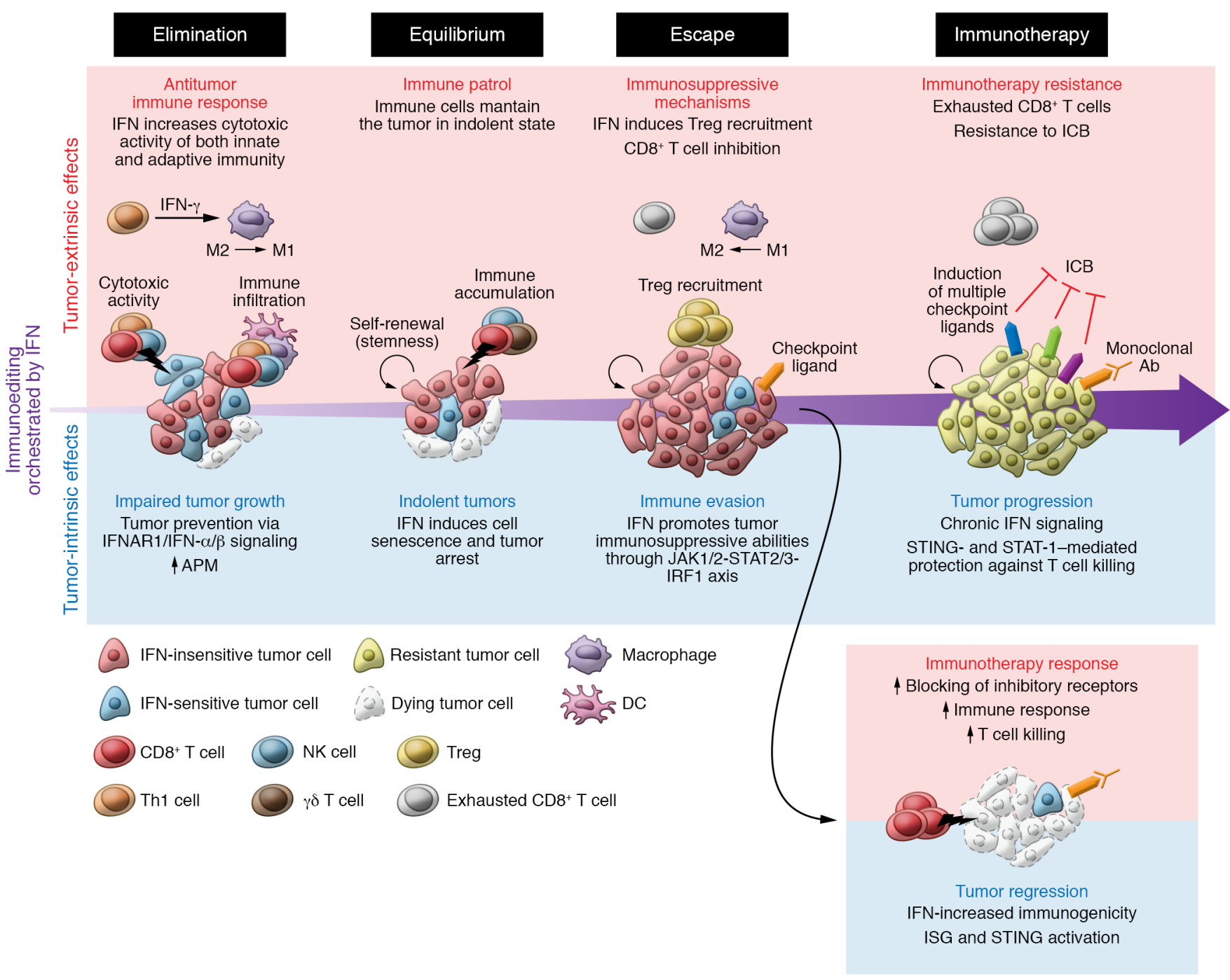

Figure 2. Tumor-extrinsic and -intrinsic effects of IFN during immunoediting. Elimination phase: IFNs orchestrate the pace of elimination by controlling cell proliferation, differentiation, and senescence; and by increasing tumor immunogenicity, immune infiltration, and adaptive immunity attack to clear tumor cells. Equilibrium phase: Remaining tumor cells, which survive immune attack, are poorly sensitive to IFN and thus less immunogenic and less visible to the adaptive immune system. Senescent cells can persist at this stage, and other IFN-nonresponsive cells can acquire stem cell abilities, such as self-renewal, maintaining the survival of this cell population contributing to tumor survival. Overall, there is a dynamic equilibrium of cell cycling and death mediated by the crosstalk of tumor and innate and adaptive immunity. Escape phase: IFN-insensitive proliferative clones, which also express immunosuppressive ligands to evade adaptive immunity, burst out. Tumor-extrinsic effects of IFN are mediated mainly by dendritic cells and macrophages. An immunosuppressive microenvironment leads to the expression of immunosuppressive receptors in CD8 ${ }^{+} \mathrm{T}$ cells, reducing the immune attack. Immunotherapy: During immunotherapy, the immune pressure is accentuated, leading to further immunoediting. Acute IFN signaling increases tumor immunogenicity, which turns cancer cells vulnerable to immune attack, favoring immunotherapy response and tumor regression. On the other hand, immunoedited cells are poorly differentiated and highly aggressive. Chronic IFN signaling contributes to immunosuppression by the upregulation of multiple immunosuppressive ligands, causing resistance to ICB monotherapy.

immunity orchestrated by IFN (Figure 2). Similarly, during metastatic progression the immune system can also eliminate tumor cells in an IFN-dependent manner (97). NK and T cell-mediated elimination also affects circulating and disseminated tumor cells (DTCs) (98), e.g., via perforin produced by activated NK cells (99) or the interaction of lymphocytes and Kupffer cells in the liver, promoting cytotoxic elimination of DTCs (100).

Equilibrium phase. After the elimination phase, remaining tumor cells can resist immune pressure, resulting in indolent, latent tumors. At this stage, the adaptive immune system engages in persistent surveillance of any growing clones and steadily keeps tumor growth in a dynamic equilibrium of proliferation and killing (Figure 2). This phase can last for years or even decades considering the dormancy periods observed in many human cancers (101). In this scenario, consequent IFN-insensitive cells have selective advantages to avoid immune-mediated elimination and persist for long periods. Indeed, a seminal study by Koebel et al. showed for first time that the equilibrium process led to poorly immunogenic tumors (102). WT mice treated with low doses of methylcholanthrene (MCA) that did not show clinically apparent tumors were treated with both anti-CD4/CD8 and anti-IFN- $\gamma$, and $60 \%$ formed tumors at the MCA injection site. A similar trend was seen when 
mice were treated with either anti-CD4/CD8 or anti-IFN- $\gamma$. This indicated that the activated adaptive immunity maintained tumors in a dormant equilibrium state. Notably, NK depletion did not show any effect, highlighting the crucial role of adaptive immunity in equilibrium. However, recent experiments show that innate immunity may also participate, since skin carcinogenesis in mouse models without adaptive immunity were immunoedited (103). In fact, NK cell production of IFN- $\gamma$ leads to M1 macrophage activation that activates Th1 responses and secretion of toxic agents such as NO (104). Moreover, immune cell-derived IFN- $\gamma$ and TNF- $\alpha$ not only eradicate cancer cells but also induce senescence and arrest tumor cells, contributing to the equilibrium phase $(40,105,106)$.

The equilibrium is particularly relevant in metastatic disease. First notions came from clinical observations in metastatic patients: two kidney transplant recipients developed secondary cancer metastasis that had been indolent in the donor for 16 years after surgery of the primary melanoma tumor, suggesting that withdrawal of immune pressure granted exit from immuneconstrained dormancy (107). Therefore, the equilibrium phase may explain latency periods of dormancy, which represent a challenging clinical problem. DTCs can remain for years or even decades in a dormant state in distant organs, which can be explained by a dynamic equilibrium of immune-mediated killing and tumor growth in which IFN is critical (108-110) (Figure 2). During this equilibrium phase, reactive $\mathrm{CD}^{+} \mathrm{T}$ and $\mathrm{B}$ cells produce IFN- $\gamma$ upon stimulation by indolent metastatic tumor cells in the bone marrow and lymph nodes, suggesting that the immune system remains activated (108). In addition, IFN- $\gamma$ released from the immune microenvironment might have antiproliferative effects on the tumor cells, maintaining them at low proliferative rates (108). Moreover, type I IFN maintained tumor dormancy in bone metastasis (111). This effect could also be mediated by type I IFN released from macrophages in the TME (39), since macrophages can infiltrate metastatic tumors with opposing roles (112), and IRF8-deficient macrophages allow better establishment of metastasis (113). In melanoma metastasis, it was experimentally shown that $\mathrm{CD}^{+} \mathrm{T}$ cells are responsible for maintenance of indolent metastasis in equilibrium in the lung (109). Overall, these studies shed light on the opportunity to employ immune-based therapies to avoid relapse of dormant metastasis.

Escape phase. The tumor growth and death equilibrium persist until cancer cell escape variants emerge. In this scenario, the immune system fails to control tumor outgrowth, and tumors become clinically detectable. The emergence of such mechanisms is still poorly understood because of difficulties in modeling equilibrium in experimental settings, although it is well known that reduced IFN sensitivity is critical to escape, circumventing both innate and adaptive immunity, as demonstrated in seminal studies $(16,102,114,115)$. Accordingly, the loss of antigen presentation is required to persist and escape throughout the phases (114) (Figure 2).

On the other hand, IFNs can mediate opposite effects by promoting tumor-immunosuppressive abilities critical for escape from tumor immunity. Long-term IFN exposure induces the expression of immune checkpoint ligands, which prevent chronic inflammation and autoimmune disease (9) but also drive $\mathrm{CD}^{+} \mathrm{T}$ cell inhibition and immune escape in cancer $(116,117)$. In melanoma cells, IFN- $\gamma$ signaling regulates expression of PD-L1 through the
JAK1/2-STAT2/3-IRF1 axis, whereas PD-L2 is regulated by IFN- $\beta$ and IFN- $\gamma$ through both IRF1 and STAT3, which bind directly to PD-L2 promoters and promote immunosuppression (47). Chronic IFN- $\gamma$ signaling is associated with expression of other immune checkpoint ligands via STAT1-regulated epigenetic mechanisms (118). In addition, IFN induces IDO expression, which recruits immunosuppressive Tregs in the TME (119). In the inflammatory TME established through IFN networks, tumor cells gain STAT3 activity through immune-derived IL-10, IL-6, NF- $\mathrm{BB}$, or Bcl2, which execute tumor-promoting effects such as proliferation, antiapoptotic signals, and angiogenesis (120, 121). Additionally, these secreted factors drive expansion of MDSCs and Tregs, which, together with M2 macrophages and DCs, produce immunosuppressive cytokines such as TGF- $\beta$ and IL-10 and express immunoregulatory molecules, including arginase, inducible NO synthase, and IDO $(120,121)$. Ultimately, the proinflammatory environment elicited by IFNs and tumor-intrinsic IFN insensitivity permits tumor escape and outgrowth.

Regarding metastasis, fewer studies have characterized the escape phase and IFN sensitivity. However, the loss of IRF7 in breast cancer metastatic cells was shown to be crucial for escaping $\mathrm{NK}$ and $\mathrm{CD} 8^{+} \mathrm{T}$ cell immunity in bone metastasis (122). In another study, the clonal evolution of metastasis demonstrated that clone outgrowth is largely dependent on the adaptive immune system, which is consistent with the immunoediting principles of escape (17). Alternatively, the lack of immunity ends up in non-immunoedited metastatic tumors. Therefore, not every metastatic tumor is immunoedited, and consequently, immunoedited metastases are less immunogenic, confirming the environmental influence on clonal evolution $(81,123)$. Accordingly, both scenarios align with the observation that metastatic tumors generally display lower immune activity than primary counterparts $(124,125)$ and metastatic cells have less antigen presentation (126).

Therefore, acquired IFN insensitivity is relevant in all phases of immunoediting. Accordingly, heterogeneous tumors contain small subsets of nonsensitive populations that are not eliminated, leading to selection of insensitive, aggressive clones. Indeed, CSCs reported to be insensitive to IFN may persist beyond this phase, leading to tumor initiation and progression. In fact, it was shown that CSCs are resistant to anti-CTLA-4 treatment in squamous cell carcinoma (127). Therefore, cancer immunoediting could enrich for IFN-insensitive CSC populations, underscoring the tumor-promoting consequences of immunoediting. As a result, metastatic tumors are enriched in metastasis-initiating cells with immune-evasive properties. Overall, how immune pressure shapes cancer escape mechanisms in metastasis, and the role of distinct IFN effects varying throughout the process, will require additional exploration at different stages of tumor progression. The findings might have important implications for immunotherapeutic treatments in different metastatic organs $(90,128)$.

\section{IFN functions during cancer metastasis}

Metastatic disease encompasses a cascade of complex biological steps, from tissue invasion, intravasation into the vascular system, and circulation to extravasation at distant tissues, seeding, and tissue colonization. Hence, tumor cells require distinct abilities to overcome these challenges, including an intense dialog with the 


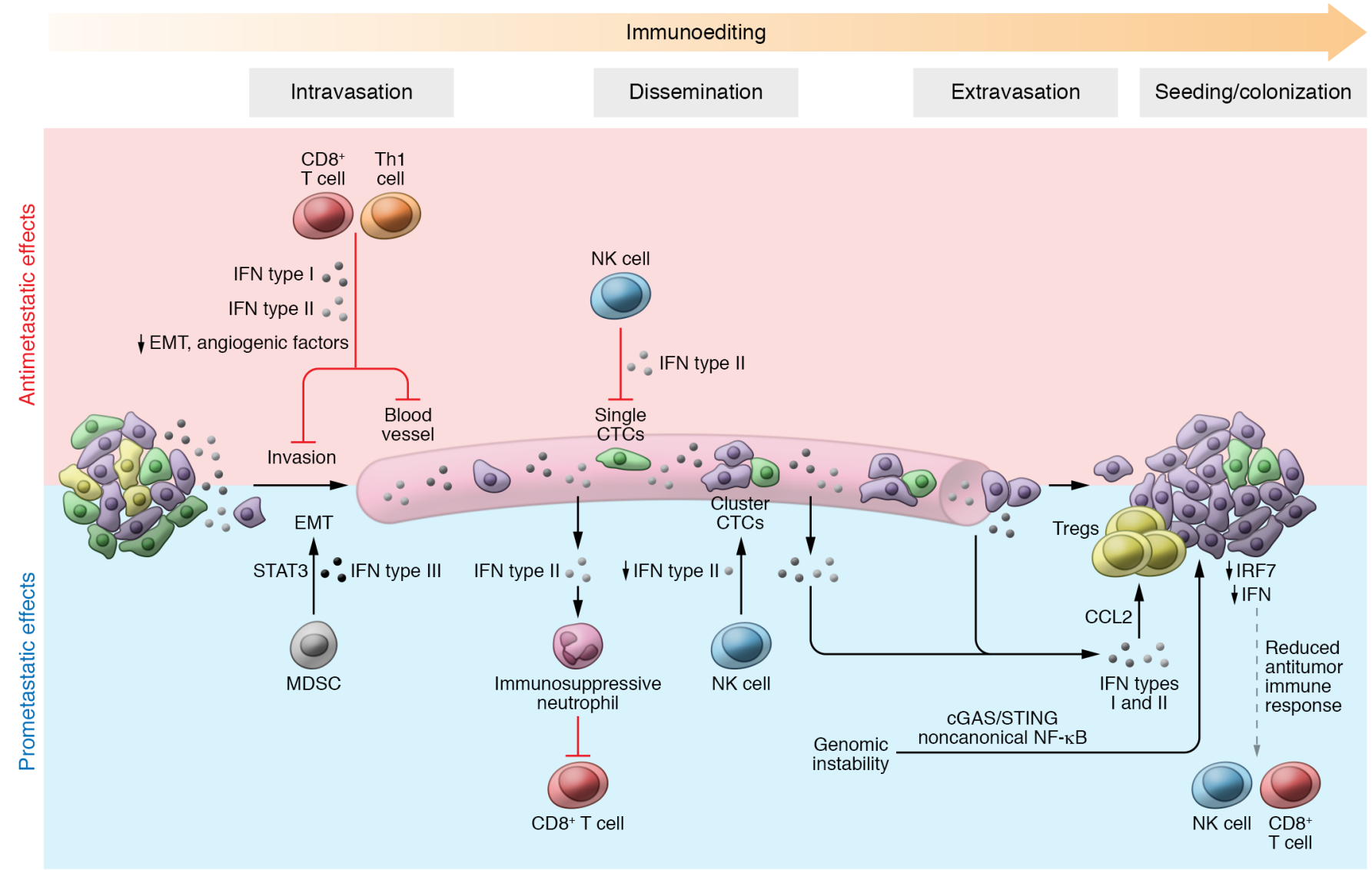

Figure 3. IFN effects during metastasis. Antimetastatic effects: IFNs might reduce tumor cell dissemination through upregulation of E-cadherin by IFN type I, thus inhibiting epithelial-mesenchymal transition (EMT). Also, CD8 ${ }^{+}$T cells and Th1 cells secrete IFN type II, which downregulates both CXCR4 and VEGF, suppressing dissemination and angiogenesis, respectively. Upon dissemination, EMT-like single circulating tumor cells (CTCS) are susceptible to NK cell-mediated killing, while CTC clusters contain epithelial-like cells that are less susceptible to NK cell-mediated cytotoxicity, causing reduced IFN- $\gamma$ production by NK cells. At the metastatic site, tumors display reduced IRF7 expression, diminishing IFN and visibility to CD8 ${ }^{+} \mathrm{T}$ and NK cell immune attack. Prometastatic effects: Myeloid-derived suppressor cells (MDSCs) release IFN type III, which activates STAT3, engaging the EMT process. IFN types I and II are produced by tumor cells, driving the recruitment of immunosuppressive neutrophils that decrease immune attack during dissemination. Also, IFN types I and II lead to CCL2 secretion and increase recruitment of Tregs to the metastatic site, supporting the seeding of tumor cells. Genomic instability triggers cGAS/STING pathways, promoting invasion and metastasis. The dynamic interaction with immunity could be the cause of tumor heterogeneity loss and the increase in clonal tumor selection driven by IFN sensitivity. Immune hostile challenges accumulate throughout the process, contributing to immunoediting.

TME $(129,130)$. Along the metastatic journey, IFNs play tumorrepressive and -promoting roles and can differ in the primary and metastatic site (131) (Figure 3).

Non-immune-directed functions. Several IFN implications have been reported to influence tumor cell proliferation, migration, and angiogenesis during metastasis (Figure 3). Besides reduction of cell proliferation and induction of apoptosis, IFN type I may contribute to the preservation of tumor cell migration by upregulating E-cadherin $(132,133)$, which is a hallmark event of epithelial-mesenchymal transition (EMT) leading to tumor invasion and dissemination (134). In addition, IFN- $\gamma$ downregulates CXCR4 and its ligand SDF-1, leading to suppression of cell migration and proliferation in head and neck carcinoma (135). Angiogenesis, a characteristic process in cancer and metastasis (136), is blocked by IFNs, thus reducing tumor growth (137-139). An interesting study used TIE2/IFNA1- expressing monocytes to deliver IFN- $\alpha$ in glioblastoma and mammary tumors, leading to reduced angiogenesis, tumor growth, and metastasis by preventing tumor cell dissemination (140). Strikingly, another report suggested that IFN- $\gamma$-mediated angiostasis facilitates the dissemination of subcutaneously implanted lung carcinoma cells (LCC1) due to perivascular disruption (141). After dissemination into the bloodstream, circulating tumor cells (CTCs) require the regulation of cell adhesion molecules (142) that are partially modulated by ISGs (e.g., via induction of VCAM-1 by IRF1) (143). By reducing CXCR4 at the metastatic sites, IFN- $\gamma$ impairs trafficking, homing, and survival of CTCs (144). At the metastatic site, depletion of Lgr5 ${ }^{+}$ cells impairs cancer plasticity of CTCs with a consequent increase in IFN signaling and reduced metastasis (145).

On the other hand, IFN signaling also promotes metastatic behaviors (143). In brain metastasis, tumor cells activate NF- $\mathrm{KB}$ and 
STAT1 pathways via astrocyte-derived, IFN- $\alpha$-promoted growth (146). Remarkably, genomic instability triggers cGAS/STING and noncanonical NF- $\kappa \mathrm{B}$, favoring a mesenchymal invasive phenotype and metastasis (147). Moreover, IFN- $\alpha$ mediates activation of quiescent hematopoietic stem cells in vivo (148) as well as prostate cancer cells in bone metastasis (111). Intriguingly, stem cell-like phenotypes respond differently to IFN stimuli with increased tumorigenic formation and aggressiveness. In contrast, differentiated tumor cells that are IFN-sensitive respond by reducing growth and increasing differentiation (39). Therefore, molecular mechanisms of IFN orchestrate divergent effects during tumorigenesis, especially during metastasis, which requires further investigation.

Immune-directed functions. The immune system controls different steps of metastasis by regulating IFN (Figure 3). IRF1 activation and IFN- $\gamma$ signaling were enriched in cytotoxic Th1 responses to prevent early tumor cell dissemination (149), suggesting that immunity actively prevents tumor dissemination. In addition, primary tumor-infiltrating NK cells produce IFN- $\gamma$ that induces the extracellular matrix protein fibronectin 1, preventing dissemination (150). Functional in vivo screening studies in mice showed how host deficiencies in the IFN-regulatory factors IRF1 and IRF7 led to defects in IFN type I signaling, which is associated with metastatic colonization. However, host IRF5 deficiency, which does not cause IFN type I deficiency, had no influence on metastasis, demonstrating an antimetastatic role of IFN type I signaling in the metastasis microenvironment (151). The delivery of IFN- $\alpha$ in MMTV-PyMT primary tumors increased infiltration and activity of innate and adaptive cytotoxic cells, preventing metastasis development (140).

In the innate compartment, IFN- $\gamma$ upregulates STING in neutrophils, promoting their killing capacity to eliminate disseminated tumor cells in the lung, preventing metastasis (152). Recent studies demonstrate NK cells' important role in immune-selective pressure by sculpting the metastatic tumor phenotype (153-155). Various studies highlight the role of IFN- $\gamma$-activated NK cells for immune surveillance of target organs, specifically recognizing and eliminating metastatic EMT-like phenotypes $(154,156)$, offering an extrinsic explanation of aggressive epithelial phenotypes observed in metastatic organs (157) (Figure 3). The deficiency in IFNAR1 expression and JAK/STAT signaling reduces NK cell-mediated antitumor immunity, enhancing breast cancer metastasis $(158,159)$. Moreover, TLR7, which can induce IFN type I (160), promotes early NK cell and late $\mathrm{CD}^{+} \mathrm{T}$ cell responses, inhibiting lung metastasis (161). Aligned with this, silencing IRF7 negatively regulates NK cellmediated immunity and $\mathrm{CD}^{+} \mathrm{T}$ cell responses, accelerating bone metastasis of breast (122) and prostate cancer (162). Therefore, multiple mechanisms involving adaptive and innate immunity take part in IFN signaling's implications in metastasis reduction.

In contrast, MDSCs induce EMT and invasion of tumor cells in an IFN- $\lambda$ - and STAT3-dependent manner to increase metastasis (163), and, intriguingly, STING/cGAS reduces MDSC accumulation, which collectively reverses EMT and metastasis (164). The loss of ELF5 - an EMT repressor - stabilizes IFNGR1, causing an increase of immunosuppressive neutrophils contributing to tumor growth and metastasis in TNBC (165). Indeed, EMT cells express and respond more strongly to IFN- $\gamma$, which increases PD-L1 to protect from adaptive immunity $(166,167)$. Once CTCs reach the secondary organ, type I IFNs induce chemokine production (e.g.,
CCL2) that favors adaptation of tumors in a fertile environment $(168,169)$ and recruitment of Tregs that promote metastasis by immunosuppression (170). Overall, the pleiotropic effects of IFN during the metastatic cascade are remarkable, and we envision that new studies applying single-cell resolution analyses will contribute to a better understanding of this complexity.

\section{IFN implications during therapy-mediated immunoediting}

Immunotherapy induces anticancer immune responses in which IFN plays a critical role. Therefore, clinical interventions alter the tumor-immune interface, determining the course of their coevolution and intensification of immunoediting (Figure 2). This was demonstrated by analysis of 68 melanoma patients treated with anti-PD-1 ICB that revealed reduced mutational burden after treatment and changes in lymphocyte $\mathrm{T}$ cell receptor repertoires (171). In tumors reentering immunoediting, nivolumab (an anti-PD-1 mAb) forced an alteration of the clonal evolution and the appearance of IFN deletions, suggesting that a genetic drift reduces IFN response, whereas in responders, IFN response was high (171). This remarkable study suggests the sculpting effects of immunotherapy-mediated immune pressure. More studies are required to corroborate these highly relevant findings, since the treatment period was only 4 weeks and longer treatments would be more appropriate to observe immunoediting as a consequence of the treatment. In addition, further considerations are required for the processing of bulk tumor data in responders versus nonresponders. Nonetheless, another study showed that deficiency in IFN- $\gamma$ responsiveness - such as loss of the APM components tapasin and HLA-A3 - appears after immunotherapy treatment of metastatic melanoma, as tumor genetic and epigenetic editing results in resistance (172). This is not surprising since the mechanisms of immunotherapy resistance widely overlap with those related to immune evasion (173), and as we highlight in this Review, IFN insensitivity is a main mechanism of immune evasion. In addition, tumor-intrinsic mechanisms of acquired immunotherapy resistance involve mutations in the IFN pathway and the APM, which is regulated by IFN signaling $(77,174)$. Supporting these findings, single-cell RNA-Seq of untreated and ICB-treated melanoma patients revealed a $\mathrm{T}$ cell exclusion and ICB resistance gene program downregulated in APM and IFN- $\gamma$ signaling genes (175). In this scenario, tumor IFN response is negatively selected and IFN-insensitive tumor populations arise, leading to immunotherapy resistance. It will be crucial to validate these findings in expanded cohorts to prove tumor evolution and progression under ICB treatment.

The different mechanisms underlying primary and acquired immunotherapy resistance are directly and indirectly governed by IFN signaling pathways (Figure 2). The activation of IFN and downstream expression of ISGs predict response to immunotherapies in preclinical and clinical studies $(22,176,177)$. In anti-PD-1 resistance studies $(23,178-180)$, genes encoding proteins implicated in IFN- $\gamma$ signaling pathways, namely Jak1, Stat1, Ifngr1, Ifngr 2, and Jak2, were hits enriched in independent CRISPR-KO screens designed for the identification of essential genes for immunotherapy resistance. Notably, Ptpn 2 and APLNR were discovered to regulate IFN signaling and immunotherapy response 


\section{Table 1. Combinatorial immunotherapeutic clinical trials using IFN and ICB}

\begin{tabular}{|c|c|c|c|c|}
\hline IFN type & Representative drug(s) & Cancer type(s) & Phase & NCT number \\
\hline \multirow[t]{10}{*}{ IFN- $\alpha$} & Atezolizumab & Metastatic NSCLC, RCC, melanoma & 1 & NCT02174172 \\
\hline & Ipilimumab & Metastatic melanoma & 1 & NCT01409174 \\
\hline & & Metastatic melanoma & $1 / I I$ & NCT01409187 \\
\hline & & Metastatic melanoma & III & NCT01274338 \\
\hline & Nivolumab & Recurrent hepatocellular carcinoma & $1 / I I$ & NCT04233840 \\
\hline & Pembrolizumab & Locally/regionally advanced/recurrent melanoma & 1 & NCT02339324 \\
\hline & & Metastatic TNBC & I & NCT035999453 \\
\hline & & Metastatic breast cancer & $1 / 11$ & NCT04418219 \\
\hline & & Metastatic TNBC, HER2+BC, brain metastasis & $\|$ & NCT04348747 \\
\hline & & Metastatic melanoma & III & NCT02506153 \\
\hline \multirow[t]{2}{*}{ IFN- $\gamma$} & Nivolumab & Advanced solid tumors & I & NCT02614456 \\
\hline & Pembrolizumab & MF, SS, synovial sarcoma & ॥ & NCT03063632 \\
\hline
\end{tabular}

HER2+BC, HER2-positive breast cancer; HNSCC, head and neck squamous cell carcinoma; MF, mycosis fungoides; NET, neuroendocrine tumors; NSCLC, non-small cell lung carcinoma; RCC, renal cell carcinoma; SS, Sézary syndrome.

in murine and human melanoma cells, respectively $(23,24)$. A similar trend was observed in anti-CTLA-4-resistant tumor cells $(77,180)$. Another CRISPR screen in B16 melanoma cells revealed ADAR1 as an RNA-editing enzyme that limited the sensing of double-stranded RNA (dsRNA), reducing IFN type I and II responses. Hence, the loss of ADAR1 overcomes resistance to anti-PD-1 therapy (181). Similarly, loss of LSD1 reduces IFN type I induced by ERV and dsRNA stress, leading to anti-PD-1 therapy response (182). In a melanoma patient cohort treated with ICB, all nonresponders with active $\mathrm{CD} 8^{+} \mathrm{T}$ cell signatures carried defects in antigen presentation and the IFN- $\gamma$ pathway (183).

The disruption of IFN- $\gamma$ signaling through acquired JAK1/2 mutations in cancer cells renders tumors insensitive to the antiproliferative and cytotoxic effects of T cells (180). After receiving ICB therapy, in particular anti-PD-1, regressed tumors have specific deleterious mutations in JAK1 and JAK2, losing IFN- $\gamma$ sensitivity (78). IFN-regulatory factors, such as IRF1, are lost during ICB with anti-CTLA-4 in melanoma patients, and the expression of JAK/ STAT inhibitors is increased (77). Other reports found that tumors of responders carrying IFNGR1 mutations still regressed (184) or that increased IFN- $\gamma$ serum levels as a result of systemic inflammation correlate with anti-PD-1 therapy progression and clinical benefit (185). A recent study using a CRISPR screen assay in cytotoxic conditions again identified IFN pathway genes as critical for ICB response, in particular Ifngr2 and Jak1, driving IFN insensitivity. As a result of lack of immune recognition, Ifngr2 mutants were selected and led to resistance to anti-PD-L1 treatment (82). This highlights immunotherapy-mediated immunoediting of IFNinsensitive cells as a mechanism of immunotherapy resistance.

In contrast, long-term exposure to IFNs and persistent activation of IFN signaling generate a cascade of secondary IFN gene pro- grams that can mediate opposing immunosuppressive functions in tumor immunity and immunotherapy (186). Strikingly, persistent IFN signaling not only leads to PD-L1 expression as previously reported (187), sensitizing tumors to anti-PD-L1, but also leads to epigenetically driven changes in STAT1 activation that stimulate multiple T cell-inhibitory ligands such as LGALS9, TNFRSF14, $\mathrm{MCH}$ class II, and CD86. The latter complements a whole set of immune checkpoints and thus mediates resistance to individual ICB and to the combination of anti-CTLA- 4 with radiotherapy (118). After radiation therapy, IFN type I is persistently induced and causes long-term expression of Serpinb9, an inhibitor of granzyme B that hence protects tumor cells from $\mathrm{T}$ cell-mediated killing with or without anti-PD-L1 treatment (188). Therefore, the divergent paths and temporal dynamics of IFN signaling are highly complex and require further revision to answer whether immunotherapy-mediated immunoediting may restore or sustain IFN sensitivity. These paradoxical effects are reflected in chemo- and radiotherapy resistance in patients with IFN-related DNA damage signatures (IRDS). IRDS positivity and thus chronic IFN signaling predict therapy resistance by reducing cytotoxic signals translating into prosurvival effects (189) and by activating tumor cell initiation pathways, such as NOTCH signaling (190).

Ultimately, IFN signaling is a core regulatory mechanism of evolving responses to conventional and immunotherapy, namely therapy-induced immunoediting (Figure 2). Overall, these therapeutic effects highlight the spatiotemporal complexity of IFN signaling and the necessity of better understanding IFN dynamics and immunoediting to exploit its application in immunotherapy (see ongoing clinical trials in Table 1) as well as for new combined strategies to personalize treatments for IFN-insensitive or -sensitive patients. 


\section{Conclusions}

Herein, we highlight the dynamic perspectives of IFN signaling in carcinogenesis, immunoediting, and metastasis as well as its duality in immunotherapy. We classify IFN insensitivity in two types, primary IFN insensitivity and acquired IFN insensitivity, that can determine the pace of tumor evolution with intrinsic and extrinsic implications. We outline acquired IFN insensitivity based on the ability of tumors to acquire insensitivity during tumor progression and metastasis reciprocally with immunoediting, while primary IFN insensitivity originates at tumor onset without progressing with immunoediting. Therefore, the more immunoediting and IFN insensitivity progress, the more strongly they convey resistance and highly aggressive tumors, which is reflected in clinical advanced stages. A better understanding of how the different types of IFN insensitivity (Figure 1) emerge in whole tumor cell populations depending on the immune context is critical since alteration of IFN signaling is a shared feature that provides cancer cells with benefits to overcome immune pressure and develop therapy resistance.

However, the duality of IF Ns' effects raises questions, because persistent IFN signaling leads to immunosuppressive effects and, thus, IFN-driven resistance might be favored during tumor evolution in direct contrast with IFN insensitivity selection. Future research should address this apparent paradox. Alternatively, the cooperation of different clonal populations within the heterogeneity of tumors - with immunosuppressive clones protecting IFN-insensitive poorly immunogenic clones - might explain increased tumor growth and resistance. IFN signaling activation strategies in combination with other therapeutic strategies such as chemotherapy, radiotherapy, or ICB may be the key factor to overcome therapy resistance, leading to clinical benefit. We envision that the dynamic comprehension of the molecular and cellular mechanisms of IFN responses during cancer progression, metastasis, and treatments will be a future cornerstone for novel immune-based therapies and tailored treatments.

\section{Acknowledgments}

We apologize to investigators if any important studies have not been cited here owing to space limitations. The work was supported by the Instituto de Salud Carlos III-FSE (MS17/00037; PI18/00014), a Spanish Association Against Cancer (AECC) LAB grant (LABAE19007CELI), and a Cancer Research Institute CLIP grant (CRI2477) to TCT.

Address correspondence to: Toni Celià-Terrassa, Cancer Program, Hospital del Mar Medical Research Institute (MM), Carrer del Dr. Aiguader, 88, 08003 Barcelona, Spain.Email: acelia@imim.es.
1. Isaacs A, Lindenmann J. Classics in oncology: virus interference: I. the interferon. CA Cancer J Clin. 1988;38(5):280-290.

2. Borden EC, et al. Interferons at age 50: past, current and future impact on biomedicine. Nat Rev Drug Discov. 2007;6(12):975-990.

3. Ivashkiv LB. IFN $\gamma$ : signalling, epigenetics and roles in immunity, metabolism, disease and cancer immunotherapy. Nat Rev Immunol. 2018;18(9):545-558.

4. Zitvogel L, Galluzzi L, Kepp O, Smyth MJ, Kroemer G. Type I interferons in anticancer immunity. Nat Rev Immunol. 2015;15(7):405-414.

5. Lazear HM, Schoggins JW, Diamond MS. Shared and distinct functions of type I and type III interferons. Immunity. 2019;50(4):907-923.

6. Parker BS, Rautela J, Hertzog PJ. Antitumour actions of interferons: implications for cancer therapy. Nat Rev Cancer. 2016;16(3):131-144.

7. Dunn GP, Koebel CM, Schreiber RD. Interferons, immunity and cancer immunoediting. Nat Rev Immunol. 2006;6(11):836-848.

8. Minn AJ. Interferons and the immunogenic effects of cancer therapy. Trends Immunol. 2015;36(11):725-737.

9. Barrat FJ, Crow MK, Ivashkiv LB. Interferon target-gene expression and epigenomic signatures in health and disease. Nat Immunol. 2019;20(12):1574-1583.

10. Ivashkiv LB, Donlin LT. Regulation of type I interferon responses. Nat Rev Immunol. 2014;14(1):36-49.

11. Larner AC, Chaudhuri A, Darnell JE. Transcriptional induction by interferon. New protein (s) determine the extent and length of the induction. J Biol Chem. 1986;2(7):453-459.

12. Burnet M. Cancer; a biological approach. I. The processes of control. Br Med J.
1957;1(5022):779-786.

13. Thomas L. Delayed hypersensitivity in health and disease. In: Lawrence HS, ed. Cellular and Humoral Aspects of the Hypersensitive States. Hoeber-Harper. 1959;529-532.

14. Dighe AS, Richards E, Old LJ, Schreiber RD. Enhanced in vivo growth and resistance to rejection of tumor cells expressing dominant negative IFN $\gamma$ receptors. Immunity. 1994;1(6):447-456.

15. Kaplan DH, et al. Demonstration of an interferon $\gamma$-dependent tumor surveillance system in immunocompetent mice. Proc Natl Acad Sci US A. 1998;95(13):7556-7561.

16. Shankaran V, et al. IFNgamma and lympohcytes prevent primary tomour development and shape tomour immunogenicity. Nature. 2001;410(6832):1107-1111.

17. Schreiber RD, Old LJ, Smyth MJ. Cancer immunoediting: integrating immunity's roles in cancer suppression and promotion. Science. 2011;331(6024):1565-1570.

18. Dunn GP, Bruce AT, Ikeda H, Old LJ, Schreiber RD. Cancer immunoediting: from immunosurveillance to tumor escape. Nat Immunol. 2002;3(11):991-998.

19. Coley WB. The treatment of malignant tumors by repeated inoculations of erysipelas: With a report of ten original cases. Am JMed Sci. 1893;105(6):487-511.

20. Ho M, Armstrong JA, Breinig MC. Interferon. Annu Rev Microbiol. 1975;29(1):131-161.

21. Borden EC. Interferons $\alpha$ and $\beta$ in cancer: therapeutic opportunities from new insights. Nat Rev Drug Discov. 2019;18(3):219-234.

22. Ayers M, et al. IFN- $\gamma$-related mRNA profile predicts clinical response to PD-1 blockade. J Clin Invest. 2017;127(8):2930-2940.

23. Manguso RT, et al. In vivo CRISPR screening identifies Ptpn 2 as a cancer immunotherapy target. Nature. 2017;547(7664):413-418.

24. Patel SJ, et al. Identification of essential genes for cancer immunotherapy. Nature. 2017;548(7669):537-542.

25 . Brockwell NK, et al. Neoadjuvant interferons: critical for effective PD-1-based immunotherapy in TNBC. Cancer Immunol Res. 2017;5(10):871-884.

26. Bald T, et al. Immune cell-poor melanomas benefit from PD-1 blockade after targeted type I IFN activation. Cancer Discov. 2014;4(6):674-687.

27. Alspach E, Lussier DM, Schreiber RD. Interferon $\gamma$ and its important roles in promoting and inhibiting spontaneous and therapeutic cancer immunity. Cold Spring Harb Perspect Biol. 2019;11(3):a028480.

28. O'Neill LAJ, Golenbock D, Bowie AG. The history of Toll-like receptors-redefining innate immunity. Nat Rev Immunol. 2013;13(6):453-460.

29. Rehwinkel J, Gack MU. RIG-I-like receptors: their regulation and roles in RNA sensing. Nat Rev Immunol. 2020;20(9):537-551.

30. Hopfner KP, Hornung V. Molecular mechanisms and cellular functions of cGAS-STING signalling Nat Rev Mol Cell Biol. 2020;21(9):501-521.

31. Kadowaki N, et al. Subsets of human dendritic cell precursors express different Toll-like receptors and respond to different microbial antigens. JExp Med. 2001;194(6):863-869.

32. Kalbasi A, Ribas A. Tumour-intrinsic resistance to immune checkpoint blockade. Nat Rev Immunol. 2020;20(1):25-39.

33. Chen HM, et al. Critical role for constitutive type I interferon signaling in the prevention of cellular transformation. Cancer Sci. 2009;100(3):449-456.

34. Chawla-Sarkar M, et al. Apoptosis and interferons: role of interferon-stimulated genes as mediators of apoptosis. Apoptosis. 2003;8(3):237-249. 
35. Sato A, Ohtsuki M, Hata M, Kobayashi E, Murakami T. Antitumor activity of IFN- $\lambda$ in murine tumor models. J Immunol. 2006;176(12):7686-7694.

36. Chin YE, Kitagawa M, Su WC, You ZH, Iwamoto Y, Fu XY. Cell growth arrest and induction of cyclin-dependent kinase inhibitor p21 WAF1/CIP1 mediated by STAT1. Science. 1996;272(5262):719-722.

37. Wang $\mathrm{W}$, et al. $\mathrm{CD} 8^{+} \mathrm{T}$ cells regulate tumour ferroptosis during cancer immunotherapy. Nature. 2019;569(7755):270-274.

38. Mullally A, et al. Depletion of Jak2V617F myeloproliferative neoplasm-propagating stem cells by interferon- $\alpha$ in a murine model of polycythemia vera. Blood. 2013;121(18):3692-3702.

39. Celià-Terrassa T, et al. Normal and cancerous mammary stem cells evade interferon-induced constraint through the miR-199a-LCOR axis. Nat Cell Biol. 2017;19(6):711-723.

40. Braumüller H, et al. T-helper-1-cell cytokines drive cancer into senescence. Nature. 2013;494(7437):361-365.

41. Greiner JW, Hand PH, Noguchi P, Fisher PB, Pestka S, Schlom J. Enhanced expression of surface tumor-associated antigens on human breast and colon tumor cells after recombinant human leukocyte $\alpha$-interferon treatment. Cancer Res. 1984;44(8):3208-3214.

42. Boyer CM, et al. Differential induction by interferons of major histocompatibility complexencoded and non-major histocompatibility complex-encoded antigens in human breast and ovarian carcinoma cell lines. Cancer Res. 1989;49(11):2928-2934.

43. Lasfar A, et al. Characterization of the mouse IFN- $\lambda$ ligand-receptor system: IFN- $\lambda$ s exhibit antitumor activity against B16 melanoma. Cancer Res. 2006;66(8):4468-4477.

44. Fellous M, Kamoun M, Bone R, Gresser I. Enhanced expression of HLA antigens and $\beta 2$ microglobulin on interferon-treated human lymphoid cells. Eur JImmunol. 1979;9(6):446-449.

45. Schiffer R, Baron J, Dagtekin G, Jahnen-Dechent W, Zwadlo-Klarwasser G. Differential regulation of the expression of transporters associated with antigen processing, TAP1 and TAP2, by cytokines and lipopolysaccharide in primary human macrophages. Inflamm Res. 2002;51(8):403-408.

46. Griffin TA, et al. Immunoproteasome assembly: cooperative incorporation of interferon $\gamma($ IFN- $\gamma$ )-inducible subunits. J Exp Med. 1998;187(1):97-104.

47. Garcia-Diaz A, et al. Interferon receptor signaling pathways regulating PD-L1 and PD-L2 expression. Cell Rep. 2017;19(6):1189-1201.

48. Wang XB, Zheng CY, Giscombe R, Lefvert AK. Regulation of surface and intracellular expression of CTLA-4 on human peripheral T cells. Scand J Immunol. 2001;54(5):453-458.

49. Jürgens B, Hainz U, Fuchs D, Felzmann T, Heitger A. Interferon-gamma-triggered indoleamine 2,3-dioxygenase competence in human monocyte-derived dendritic cells induces regulatory activity in allogeneic T cells. Blood. 2009;114(15):3235-3243.

50. Ribas A. Adaptive immune resistance: how cancer protects from immune attack. Cancer Discov.
2015;5(9):915-919.

51. Schürch C, Riether C, Amrein MA, Ochsenbein AF. Cytotoxic T cells induce proliferation of chronic myeloid leukemia stem cells by secreting interferon- $\gamma$.J Exp Med. 2013;210(3):605-621.

52. Xu YH, Li ZL, Qiu SF. IFN- $\gamma$ induces gastric cancer cell proliferation and metastasis through upregulation of integrin $\beta 3$-mediated NF- $\mathrm{B}$ signaling. Transl Oncol. 2018;11(1):182-192.

53. Evans MK, et al. Expression of SOCS1 and SOCS3 genes is differentially regulated in breast cancer cells in response to proinflammatory cytokine and growth factor signals. Oncogene. 2007;26(13):1941-1948.

54. Ito T, Amakawa R, Inaba M, Ikehara S, Inaba K, Fukuhara S. Differential regulation of human blood dendritic cell subsets by IFNs. J Immunol. 2001;166(5):2961-2969.

55. Hervas-Stubbs S, et al. CD8 T cell priming in the presence of IFN- $\alpha$ renders CTLs with improved responsiveness to homeostatic cytokines and recall antigens: important traits for adoptive $\mathrm{T}$ cell therapy. J Immunol. 2012;189(7):3299-3310.

56. Fuertes MB, et al. Host type I IFN signals are required for antitumor $\mathrm{CD} 8+\mathrm{T}$ cell responses through CD $8 \alpha+$ dendritic cells. J Exp Med. 2011;208(10):2005-2016.

57. Agnello D, et al. Cytokines and transcription factors that regulate $\mathrm{T}$ helper cell differentiation: new players and new insights. J Clin Immunol. 2003;23(3):147-161.

58. Duluc D, et al. Interferon- $\gamma$ reverses the immunosuppressive and protumoral properties and prevents the generation of human tumor-associated macrophages. Int J Cancer. 2009;125(2):367-373.

59. Zoglmeier C, et al. CpG blocks immunosuppression by myeloid-derived suppressor cells in tumor-bearing mice. Clin Cancer Res. 2011;17(7):1765-1775.

60. Sisirak V, et al. Impaired IFN- $\alpha$ production by plasmacytoid dendritic cells favors regulatory T-cell expansion that may contribute to breast cancer progression. Cancer Res. 2012;72(20):5188-5197.

61. Mattei F, Schiavoni G, Belardelli F, Tough DF. IL15 is expressed by dendritic cells in response to type I IFN, double-stranded RNA, or lipopolysaccharide and promotes dendritic cell activation. $J$ Immunol. 2001;167(3):1179-1187.

62. Nguyen KB, et al. Coordinated and distinct roles for IFN- $\alpha \beta$, IL-12, and IL-15 regulation of $\mathrm{NK}$ cell responses to viral infection. J Immunol. 2002;169(8):4279-4287.

63. Edwards BS, Merritt JA, Fuhlbrigge RC, Borden EC. Low doses of interferon alpha result in more effective clinical natural killer cell activation. JClin Invest. 1985;75(6):1908-1913.

64. Munn DH, Mellor AL. IDO in the tumor microenvironment: inflammation, counter-regulation, and tolerance. Trends Immunol. 2016;37(3):193-207.

65. Cripps JG, Wang J, Maria A, Blumenthal I, Gorham JD. Type $1 \mathrm{~T}$ helper cells induce the accumulation of myeloid-derived suppressor cells in the inflamed Tgfb1 knockout mouse liver. Hepatology. 2010;52(4):1350-1359.

66. Mundy-Bosse BL, et al. Myeloid-derived suppressor cell inhibition of the IFN response in tumor-bearing mice. Cancer Res.
2011;71(15):5101-5110.

67. James CD, He J, Carlbom E, Nordenskjold M, Cavenee WK, Collins VP. Chromosome 9 deletion mapping reveals interferon alpha and interferon beta-1 gene deletions in human glial tumors. Cancer Res. 1991;51(6):1684-1688.

68. Linge C, Gewert D, Rossmann C, Bishop JA, Crowe JS. Interferon system defects in human malignant melanoma. Cancer Res. 1995;55(18):4099-4104.

69. Matin SF, et al. Impaired $\alpha$-interferon signaling in transitional cell carcinoma: lack of p48 expression in 5637 cells. Cancer Res. 2001;61(5):2261-2266.

70. Josefa Bello M, et al. Molecular and cytogenetic analysis of chromosome 9 deletions in 75 malignant gliomas. Genes Chromosomes Cancer. 1994;9(1):33-41.

71. Satoh A, et al. Epigenetic inactivation of class II transactivator (CIITA) is associated with the absence of interferon- $\gamma$-induced HLA-DR expression in colorectal and gastric cancer cells. Oncogene. 2004;23(55):8876-8886.

72. Lu R, Au WC, Yeow WS, Hageman N, Pitha PM. Regulation of the promoter activity of interferon regulatory factor-7 gene. Activation by interferon snd silencing by hypermethylation. J Biol Chem. 2000;275(41):31805-31812.

73. Lee KY, et al. Epigenetic disruption of interferon- $\gamma$ response through silencing the tumor suppressor interferon regulatory factor 8 in nasopharyngeal, esophageal and multiple other carcinomas. Oncogene. 2008;27(39):5267-5276.

74. Adámková L, Součkova K, Kovařík J. Transcription protein STAT1: biology and relation to cancer. Folia Biol. 2007;53(1):1-6.

75. Widschwendter A, Tonko-Geymayer S, Welte T, Daxenbichler G, Marth C, Doppler W. Prognostic significance of signal transducer and activator of transcription 1 activation in breast cancer. Clin Cancer Res. 2002;8(10):3065-3074.

76. Simpson JA, Al-Attar A, Watson NF, Scholefield JH, Ilyas M, Durrant LG. Intratumoral T cell infiltration, MHC class I and STAT1 as biomarkers of good prognosis in colorectal cancer. Gut. 2010;59(7):926-933.

77. Gao J, et al. Loss of IFN- $\gamma$ pathway genes in tumor cells as a mechanism of resistance to antiCTLA-4 therapy. Cell. 2016;167(2):397-404.e9.

78. Zaretsky JM, et al. Mutations associated with acquired resistance to PD-1 blockade in melanoma. NEnglJMed. 2016;375(9):819-829.

79. Shin DS, et al. Primary resistance to PD-1 blockade mediated by JAK1/2 mutations. Cancer Discov. 2017;7(2):188-201.

80. Zitzmann K, et al. SOCS1 silencing enhances antitumor activity of type I IFNs by regulating apoptosis in neuroendocrine tumor cells. Cancer Res. 2007;67(10):5025-5032.

81. Angelova M, et al. Evolution of metastases in space and time under immune selection. Cell. 2018;175(3):751-765.e16.

82. Williams JB, et al. Tumor heterogeneity and clonal cooperation influence the immune selection of IFN- $\gamma$-signaling mutant cancer cells. Nat Commun. 2020;11(1):602.

83. Osborn JL, Greer SF. Metastatic melanoma cells evade immune detection by silencing STAT1. Int 
J Mol Sci. 2015;16(2):4343-4361.

84. Celià-Terrassa T. Mammary stem cells and breast cancer stem cells: molecular connections and clinical implications. Biomedicines. 2018;6(2):50.

85. Doherty MR, et al. Interferon-beta represses cancer stem cell properties in triple-negative breast cancer. Proc Natl Acad Sci U S A. 2017;114(52):13792-13797.

86. Li J, et al. CD133+ liver cancer stem cells resist interferon-gamma-induced autophagy. BMC Cancer. 2016;16:15.

87. Dunn GP, Old LJ, Schreiber RD. The three Es of cancer immunoediting. Annu Rev Immunol. 2004;22:329-360.

88. Galon J, Bruni D. Tumor immunology and tumor evolution: intertwined histories. Immunity. 2020;52(1):55-81.

89. Birkbak NJ, McGranahan N. Cancer genome evolutionary trajectories in metastasis. Cancer Cell. 2020;37(1):8-19.

90. Hegde PS, Chen DS. Top 10 challenges in cancer immunotherapy. Immunity. 2020;52(1):17-35.

91. Bindea G, et al. Spatiotemporal dynamics of intratumoral immune cells reveal the immune landscape in human cancer. Immunity. 2013;39(4):782-795.

92. Zhang AW, et al. Interfaces of malignant and immunologic clonal dynamics in ovarian cancer. Cell. 2018;173(7):1755-1769.e22.

93. Jiménez-Sánchez A, et al. Heterogeneous tumor-immune microenvironments among differentially growing metastases in an ovarian cancer patient. Cell. 2017;170(5):927-938.e20.

94. Lou Y, et al. Restoration of the expression of transporters associated with antigen processing in lung carcinoma increases tumor-specific immune responses and survival. Cancer Res. 2005;65(17):7926-7933.

95. Li W, Lewis-Antes A, Huang J, Balan M, Kotenko SV. Regulation of apoptosis by type III interferons. Cell Prolif. 2008;41(6):960-979.

96. Thapa RJ, et al. Interferon-induced RIP1/ RIP3-mediated necrosis requires PKR and is licensed by FADD and caspases. Proc Natl Acad Sci U S A. 2013;110(33):E3109-E3118.

97. Park CG, Hartl CA, Schmid D, Carmona EM, Kim HJ, Goldberg MS. Extended release of perioperative immunotherapy prevents tumor recurrence and eliminates metastases. Sci Transl Med. 2018;10(433):eaar1916.

98. Mohme M, Riethdorf S, Pantel K. Circulating and disseminated tumour cells - mechanisms of immune surveillance and escape. Nat Rev Clin Oncol. 2017;14(3):155-167.

99. Brodbeck T, Nehmann N, Bethge A, Wedemann G, Schumacher U. Perforin-dependent direct cytotoxicity in natural killer cells induces considerable knockdown of spontaneous lung metastases and computer modelling-proven tumor cell dormancy in a HT29 human colon cancer xenograft mouse model. Mol Cancer. 2014;13:244.

100. Bayón LG, Izquierdo MA, Sirovich I, van Rooijen $\mathrm{N}$, Beelen RH, Meijer S. Role of Kupffer cells in arresting circulating tumor cells and controlling metastatic growth in the liver. Hepatology. 1996;23(5):1224-1231.

101.Loeb LA, Loeb KR, Anderson JP. Multiple mutations and cancer. Proc Natl Acad Sci US A.
2003;100(3):776-781.

102. Koebel CM, et al. Adaptive immunity maintains occult cancer in an equilibrium state. Nature. 2007;450(7171):903-907.

103. Kubick BJ, Fan X, Crouch A, McCarthy R, Roop DR. Tracing the equilibrium phase of cancer immunoediting in epidermal neoplasms via longitudinal intravital imaging. J Invest Dermatol. 2020;140(4):891-900.e10.

104.O'Sullivan T, et al. Cancer immunoediting by the innate immune system in the absence of adaptive immunity. J Exp Med. 2012;209(10):1869-1882.

105. Müller-Hermelink N, et al. TNFR1 signaling and IFN- $\gamma$ signaling determine whether T cells induce tumor dormancy or promote multistage carcinogenesis. Cancer Cell . 2008;13(6):507-518.

106.Brenner E, et al. Cancer immune control needs senescence induction by interferon-dependent cell cycle regulator pathways in tumours. Nat Commun. 2020;11(1):1335.

107. MacKie RM, Reid R, Junor B. Fatal melanoma transferred in a donated kidney 16 years after melanoma surgery. $N$ Engl J Med. 2003;348(6):567-568.

108. Müller M, Gounari F, Prifti S, Hacker HJ, Schirrmacher V, Khazaie K. EblacZ tumor dormancy in bone marrow and lymph nodes: active control of proliferating tumor cells by CD8+ immune T cells. Cancer Res. 1998;58(23):5439-5446.

109. Eyles J, et al. Tumor cells disseminate early, but immunosurveillance limits metastatic outgrowth, in a mouse model of melanoma. J Clin Invest. 2010;120(6):2030-2039.

110.Aguirre-Ghiso JA. Models, mechanisms and clinical evidence for cancer dormancy. Nat Rev Cancer. 2007;7(11):834-846.

111. Owen KL, et al. Prostate cancer cell-intrinsic interferon signaling regulates dormancy and metastatic outgrowth in bone. EMBO Rep. 2020;21(6):e50162.

112. Qian BZ, Pollard JW. Macrophage diversity enhances tumor progression and metastasis. Cell. 2010;141(1):39-51.

113. Twum DYF, et al. IFN regulatory factor-8 expression in macrophages governs an antimetastatic program. JCI Insight. 2019;4(3):e124267.

114. DuPage M, Mazumdar C, Schmidt LM, Cheung AF, Jacks T. Expression of tumour-specific antigens underlies cancer immunoediting. Nature. 2012;482(7385):405-409.

115. Matsushita $\mathrm{H}$, et al. Cancer exome analysis reveals a T-cell-dependent mechanism of cancer immunoediting. Nature. 2012;482(7385):400-404.

116. Pardoll DM. The blockade of immune checkpoints in cancer immunotherapy. Nat Rev Cancer. 2012;12(4):252-264.

117. Blank C, et al. PD-L1/B7H-1 inhibits the effector phase of tumor rejection by $\mathrm{T}$ cell receptor (TCR) transgenic CD8+ T cells. Cancer Res. 2004;64(3):1140-1145.

118. Benci JL, et al. Tumor interferon signaling regulates a multigenic resistance program to immune checkpoint blockade. Cell. 2016;167(6):1540-1554.e12.

119. Spranger S. et al. Up-regulation of PD-L1, IDO, and Tregs in the melanoma tumor microenvironment is driven by $\mathrm{CD}^{+} \mathrm{T}$ cells. Sci Transl Med. 2013;5(200):200ra116-200ra116.
120. Yu H, Pardoll D, Jove R. STATs in cancer inflammation and immunity: a leading role for STAT3. Nat Rev Cancer. 2009;9(11):798-809.

121. Avalle L, Camporeale A, Camperi A, Poli V. STAT3 in cancer: a double edged sword. Cytokine. 2017;98:42-50.

122. Bidwell BN, et al. Silencing of Irf7 pathways in breast cancer cells promotes bone metastasis through immune escape. Nat Med. 2012;18(8):1224-1231.

123. van der Heijden M, et al. Spatiotemporal regulation of clonogenicity in colorectal cancer xenografts. Proc Natl Acad Sci U S A. 2019;116(13):6140-6145.

124.Szekely B, et al. Immunological differences between primary and metastatic breast cancer. Ann Oncol. 2018;29(11):2232-2239.

125. Savas P, et al. Single-cell profiling of breast cancer $T$ cells reveals a tissue-resident memory subset associated with improved prognosis. Nat Med. 2018;24(7):986-993.

126.Pantel K, et al. Frequent down-regulation of major histocompatibility class I antigen expression on individual micrometastatic carcinoma cells. Cancer Res. 1991;51(17):4712-4715.

127. Miao Y, et al. Adaptive immune resistance emerges from tumor-initiating stem cells. Cell. 2019;177(5):1172-1186.e14.

128.Zhou SN, et al. Comparison of immune microenvironment between colon and liver metastatic tissue in colon cancer patients with liver metastasis [published online March 19, 2020]. Dig Dis Sci. https://doi.org/10.1007/s10620-020-06203-8.

129. Celià-Terrassa T, Kang Y. Distinctive properties of metastasis-initiating cells. Genes Dev. 2016;30(8):892-908.

130. Quail DF, Joyce JA. Microenvironmental regulation of tumor progression and metastasis. Nat Med. 2013;19(11):1423-1437.

131. Ryd W, Hagmar B, Lundgren E, Strannegård O. Discrepant effects of interferon murine syngeneic ascites tumors and their solid metastasizing counterparts. Int J Cancer. 1979;23(3):397-401.

132. Masuda T, et al. Up-regulation of E-cadherin and $\beta$-catenin in human hepatocellular carcinoma cell lines by sodium butyrate and interferon- $\alpha$. Vitr Cell Dev Biol Anim. 2000;36(6):387-394.

133. Padovan E, et al. Interferon stimulated gene 15 constitutively produced by melanoma cells induces e-cadherin expression on human dendritic cells. Cancer Res. 2002;62(12):3453-3458.

134. Kalluri R, Weinberg RA. The basics of epithelial-mesenchymal transition. JClin Invest. 2009;119(6):1420-1428.

135. Katayama A, Ogino T, Bandoh N, Nonaka S, Harabuchi Y. Expression of CXCR4 and its down-regulation by IFN- $\gamma$ in head and neck squamous cell carcinoma. Clin Cancer Res. 2005;11(8):2937-2946.

136. Gupta GP, Massagué J. Cancer metastasis: building a framework. Cell. 2006;127(4):679-695.

137. Deng J, et al. IFN $\gamma$-responsiveness of endothelial cells leads to efficient angiostasis in tumours involving down-regulation of Dll4. J Pathol. 2014;233(2):170-182.

138. Lu Y, et al. Responsiveness of stromal fibroblasts to IFN- $\gamma$ blocks tumor growth via angiostasis. JImmunol. 2009;183(10):6413-6421. 
139. Qin Z, Blankenstein T. CD4+ T cell-mediated tumor rejection involves inhibition of angiogenesis that is dependent on IFN $\gamma$ receptor expression by nonhematopoietic cells. Immunity. 2000;12(6):677-686.

140. De Palma M, et al. Tumor-targeted interferon- $\alpha$ delivery by Tie2-expressing monocytes inhibits tumor growth and metastasis. Cancer Cell. 2008;14(4):299-311.

141. Ni C, et al. Accelerated tumour metastasis due to interferon- $\gamma$ receptor-mediated dissociation of perivascular cells from blood vessels. J Pathol. 2017;242(3):334-346.

142.Desgrosellier JS, Cheresh DA. Integrins in cancer: biological implications and therapeutic opportunities. Nat Rev Cancer. 2010;10(1):9-22.

143. Yan R, et al. Endothelial interferon regulatory factor 1 regulates lipopolysaccharide-induced VCAM-1 expression independent of $\mathrm{NF} \kappa \mathrm{B}$. J Innate Immun. 2017;9(6):546-560.

144.Ahmed MI, Harvey JR, Kirby J, Ali S, Lennard TWJ. O-98 role of the chemokine receptor CXCR4 in breast cancer metastasis. EJC Suppl. 2007;5(3):30.

145. de Sousa e Melo F, et al. A distinct role for Lgr5 stem cells in primary and metastatic colon cancer. Nature. 2017;543(7647):676-680.

146.Chen Q, et al. Carcinoma-astrocyte gap junctions promote brain metastasis by cGAMP transfer. Nature. 2016;533(7604):493-498.

147. Bakhoum SF, et al. Chromosomal instability drives metastasis through a cytosolic DNA response. Nature. 2018;553(7689):467-472.

148.Essers MAG, et al. IFN $\alpha$ activates dormant haematopoietic stem cells in vivo. Nature. 2009;458(7240):904-908.

149. Pagès F, et al. Effector memory T cells, early metastasis, and survival in colorectal cancer. N Engl J Med. 2005;353(25):2654-2666.

150. Glasner A, et al. NKp46 receptor-mediated interferon- $\gamma$ production by natural killer cells increases fibronectin 1 to alter tumor architecture and control metastasis. Immunity. 2018;48(1):107-119.e4.

151. van der Weyden L, et al. Genome-wide in vivo screen identifies novel host regulators of metastatic colonization. Nature. 2017;541(7636):233-236.

152. Hagerling C, et al. Immune effector monocyte-neutrophil cooperation induced by the primary tumor prevents metastatic progres sion of breast cancer. Proc Natl Acad Sci U S A. 2019;116(43):21704-21714.

153. Laughney AM, et al. Regenerative lineages and immune-mediated pruning in lung cancer metastasis. Nat Med. 2020;26(2):259-269.

154. Lo HC, et al. Resistance to natural killer cell immunosurveillance confers a selective advantage to polyclonal metastasis. Nat Cancer. 2020;1(7):709-722.

155. Nakamura K, Smyth MJ. Immunoediting of cancer metastasis by NK cells. Nat Cancer. 2020;1(7):670-671.

156. Chockley PJ, Chen J, Chen G, Beer DG, Standiford TJ, Keshamouni VG. Epithelial-mesenchymal transition leads to NK cell-mediated metastasis-specific immunosurveillance in lung cancer.
JClin Invest. 2018;128(4):1384-1396.

157. Celià-Terrassa T, Jolly MK. Cancer stem cells and epithelial-to-mesenchymal transition in cancer metastasis. Cold Spring Harb Perspect Med. 2020;10(7):a036905.

158. Bottos A, et al. Decreased NK-cell tumour immunosurveillance consequent to JAK inhibition enhances metastasis in breast cancer models. Nat Commun. 2016;7:12258.

159. Rautela J, et al. Loss of host type-I IFN signaling accelerates metastasis and impairs NK-cell antitumor function in multiple models of breast cancer. Cancer Immunol Res. 2015;3(11):1207-1217.

160. Ning S, Pagano JS, Barber GN. IRF7: activation, regulation, modification and function. Genes Immun. 2011;12(6):399-414.

161. Hosoya T, et al. Induction of oligoclonal $\mathrm{CD} 8 \mathrm{~T}$ cell responses against pulmonary metastatic cancer by a phospholipid-conjugated TLR7 agonist. Proc Natl Acad Sci U S A 2018;115(29):E6836-E6844.

162.Zhao Y, Chen W, Zhu W, Meng H, Chen J, Zhang $\mathrm{J}$. Overexpression of interferon regulatory factor 7 (IRF7) reduces bone metastasis of prostate cancer cells in mice. Oncol Res. 2017;25(4):511-522.

163. Mucha J, Majchrzak K, Taciak B, Hellmén E, Król M. MDSCs mediate angiogenesis and predispose canine mammary tumor cells for metastasis via IL-28/IL-28RA (IFN- $\lambda$ ) signaling. PLoS One. 2014;9(7):e103249.

164. Cheng $\mathrm{H}$, et al. Activation of STING by cGAMP regulates MDSCs to suppress tumor metastasis via reversing epithelial-mesenchymal transition. Front Oncol. 2020;10:896.

165.Singh S, et al. Loss of ELF5-FBXW7 stabilizes IFNGR1 to promote the growth and metastasis of triple-negative breast cancer through interferon- $\gamma$ signalling. Nat Cell Biol. 2020;22(5):591-602.

166. Lou Y, et al. Epithelial-mesenchymal transition is associated with a distinct tumor microenvironment including elevation of inflammatory signals and multiple immune checkpoints in lung adenocarcinoma. Clin Cancer Res. 2016;22(14):3630-3642.

167. Chen L, et al. Metastasis is regulated via microRNA-200/ZEB1 axis control of tumour cell PD-L1 expression and intratumoral immunosuppression. Nat Commun. 2014;5(1):1-12.

168. Lin TH, et al. CCL2 increases $\alpha v \beta 3$ integrin expression and subsequently promotes prostate cancer migration. Biochim Biophys Acta Gen Subj. 2013;1830(10):4917-4927.

169. Craig MJ, Loberg RD. CCL2 (monocyte chemoattractant protein-1) in cancer bone metastases. Cancer Metastasis Rev. 2006;25(4):611-619.

170.Yang P, et al. TGF- $\beta$-miR-34a-CCL22 signaling-induced treg cell recruitment promotes venous metastases of HBV-positive hepatocellular carcinoma. Cancer Cell. 2012;22(3):291-303.

171. Riaz N, et al. Tumor and microenvironment evolution during immunotherapy with nivolumab. Cell. 2017;171(4):934-949.e16.

172. Chang CC, et al. Multiple structural and epigenetic defects in the human leukocyte antigen class I antigen presentation pathway in a recurrent metastatic melanoma following immunotherapy.
J Biol Chem . 2015;290(44):26562-26575.

173. O'Donnell JS, Teng MWL, Smyth MJ. Cancer immunoediting and resistance to T cellbased immunotherapy. Nat Rev Clin Oncol. 2019;16(3):151-167.

174. Sharma P, Hu-Lieskovan S, Wargo JA, Ribas A. Primary, adaptive, and acquired resistance to cancer immunotherapy. Cell. 2017;168(4):707-723.

175. Jerby-Arnon L, et al. A cancer cell program promotes T cell exclusion and resistance to checkpoint blockade. Cell. 2018;175(4):984-997.e24.

176. Vadakekolathu J, et al. Immune landscapes predict chemotherapy resistance and immunotherapy response in acute myeloid leukemia. Sci Transl Med. 2020;12(546):eaaz0463.

177. Cloughesy TF, et al. Neoadjuvant anti-PD-1 immunotherapy promotes a survival benefit with intratumoral and systemic immune responses in recurrent glioblastoma. Nat Med. 2019;25(3):477-486.

178. Pan D, et al. A major chromatin regulator determines resistance of tumor cells to T cell-mediated killing. Science. 2018;359(6377):770-775.

179. Vredevoogd DW, et al. Augmenting immunotherapy impact by lowering tumor TNF cytotoxicity threshold. Cell. 2019;178(3):585-599.e15.

180. Sucker A, et al. Acquired IFN $\gamma$ resistance impairs anti-tumor immunity and gives rise to T-cell-resistant melanoma lesions. Nat Commun. 2017;8:15440.

181. Ishizuka JJ, et al. Loss of ADAR1 in tumours overcomes resistance to immune checkpoint blockade. Nature. 2019;565(7737):43-48.

182.Sheng W, et al. LSD1 Ablation stimulates antitumor immunity and enables checkpoint blockade. Cell. 2018;174(3):549-563.e19.

183.Sade-Feldman M, et al. Defining T cell states associated with response to checkpoint immunotherapy in melanoma. Cell. 2018;175(4):998-1013.e20.

184. Hellmann MD, et al. Genomic features of response to combination immunotherapy in patients with advanced non-small-cell lung cancer. Cancer Cell. 2018;33(5):843-852.e4.

185. Huang AC, et al. T-cell invigoration to tumour burden ratio associated with anti-PD-1 response. Nature. 2017;545(7652):60-65.

186. Minn AJ, Wherry EJ. Combination cancer therapies with immune checkpoint blockade: convergence on interferon signaling. Cell. 2016;165(2):272-275

187. Benci JL, et al. Opposing functions of interferon coordinate adaptive and innate immune responses to cancer immune checkpoint blockade. Cell. 2019;178(4):933-948.e14.

188. Chen J, Cao Y, Markelc B, Kaeppler J, Vermeer JA, Muschel RJ. Type I IFN protects cancer cells from CD8+ T cell-mediated cytotoxicity after radiation. JClin Invest. 2019;129(10):4224-4238.

189. Weichselbaum RR, et al. An interferon-related gene signature for DNA damage resistance is a predictive marker for chemotherapy and radiation for breast cancer. Proc Natl Acad Sci US A. 2008;105(47):18490-18495.

190. Boelens MC, et al. Exosome transfer from stromal to breast cancer cells regulates therapy resistance pathways. Cell. 2014;159(3):499-513. 